\title{
Plataforma Blackboard: treinamento dos professores para a eficácia na EaD
}

\author{
Daniel Serravalle de Sá \\ (University of Manchester) \\ daniel.serravalle@manchester.ac.uk
}

\section{Resumo:}

O presente artigo faz considerações sobre o uso da plataforma Blackboard Academic Suite como ferramenta de ensino no âmbito do Departamento de Espanhol, Português e Estudos Latino-Americanos (SPLAS) na Universidade de Manchester. O que se oferece é um depoimento da experiência do autor enquanto um professor-usuário dessa tecnologia aplicada ao ensino. Reflete-se aqui sobre as funcionalidades da plataforma e a questão do treinamento necessário para utilização plena do programa e o sucesso da experiência educativa.

Palavras-chave: Blackboard Academic Suite, treinamento, Educação a distância (EaD) .

\section{Abstract:}

This paper considers the use of Blackboard Academic Suite as a teaching tool in the Department of Spanish and Portuguese and Latin American Studies (SPLAS) at the University of Manchester. The author states his experience as teacher who used such technology applied to education. The author proposes reflections about Blackboard's functionalities and the matter of training, which is crucial for a throrough use of the programme and the success of the educational experience.

Keywords: Blackboard Academic Suite, training, e-learning.

Para fins de contextualização, o presente artigo tem como objetivo relatar uma experiência específica do autor durante o período em que exerceu a função de Leitor 
brasileiro no exterior. ${ }^{1}$ No ano de 2008 a Universidade de Manchester, que vinha trabalhando com a plataforma acadêmica WebCT, realizou uma migração do antigo sistema para a plataforma Blackboard Academic Suite. O que se oferece aqui é um depoimento vivencial de um professor que acompanhou a transferência do sistema e pode observar a maneira com que a Universidade de Manchester lidou com a implantação do novo programa e com a questão do treinamento. O objetivo da Universidade era treinar professores para o desenvolvimento de cursos complementares às aulas presenciais. O relato a seguir diz respeito ao que foi observado especificamente no âmbito do Departamento de Espanhol, Português e Estudos Latino-Americanos - Spanish, Portuguese and Latin American Studies - doravante SPLAS. Destacam-se neste artigo as possibilidades do Blackboard enquanto ferramenta de ensino e a questão do treinamento de professores enquanto a chave para o êxito de um modelo de ensino baseado na web.

Por uma breve apresentação do software, o Blackboard é um ambiente virtual de aprendizagem (AVA) baseado na Internet. Sua função é facilitar a criação e gestão de cursos online proporcionando recursos multidirecionais para a construção da experiência educativa. Todo o conteúdo, as tarefas de ensino, a interação entre professor e alunos são realizados dentro desse ambiente virtual. A plataforma Blackboard é um programa pago, todavia, existem outras plataformas semelhantes disponíveis no mercado que são gratuitas e de código aberto, a exemplo do Moodle.

\footnotetext{
1 O autor foi selecionado para a função segundo os critérios do edital DRI/ CGCI n . 10/2006 e ocupou, de 2007 a 2009, a posição de Leitor brasileiro na Inglaterra, mais precisamente na University of Manchester, no departamento de Spanish, Portuguese and Latin American Studies (SPLAS), da faculdade de Languages, Linguistics and Cultures (SLLC). O Leitorado Brasileiro é um programa de divulgação cultural e linguística cuja seleção pública é organizada pela Divisão de Promoção da Língua Portuguesa (DPLP), uma secretaria dentro do Departamento Cultural do Ministério das Relações Exteriores (DC/MRE).
} 
Vale à pena ressaltar que, em sua totalidade, o Blackboard é um sistema de gestão acadêmica, o qual, além dos recursos didáticos, oferece ferramentas administrativas para o gerenciamento de cursos. O software possibilita a integração de diferentes setores de uma instituição de ensino sob um só sistema. A visualização e o controle de todas as informações referentes a um curso - matrícula, notas, frequência dos alunos, etc. - poderiam ser compartilhadas entre os ministrantes do curso e os administradores da faculdade, através da associação com o sistema Lyceum. De modo inverso, seria possível que os professores acessassem os dados pessoais e financeiros que os gestores administrativos possuem sobre os alunos. Teoricamente, a plataforma Blackboard permitiria a unificação completa das partes administrativa, financeira e acadêmica, de modo que, o grau de abertura para o compartilhamento das informações se resumiria apenas em uma questão de política institucional.

$\mathrm{Na}$ Universidade de Manchester, essa integração total não ocorre, possivelmente, porque uma abertura dessa magnitude implicaria em reestruturações nos diferentes setores e nos cargos da instituição. Os professores não têm acesso às informações pessoais dos alunos, nem os gestores administrativos podem acessar a situação acadêmica dos alunos no decorrer do semestre. Ao final do semestre as notas e a frequência dos alunos ainda são passadas do professor para coordenação de forma tradicional, via email, que posteriormente as insere no sistema. Não obstante, há indicações que no futuro essa tarefa deixará de ser da secretaria acadêmica e passará a ser do professor, o qual assumirá a responsabilidade de colocar as 
notas das suas turmas no sistema, redefinindo assim algumas funções empregatícias na Universidade de Manchester.

Discute-se abaixo os principais recursos que a plataforma tem a oferecer enquanto ambiente virtual capaz de dar apoio a um modelo de ensino que se dá além da sala de aula, e, propõe-se uma reflexão sobre a necessidade de preparar os professores adequadamente para a utilização dos diferentes recursos que a plataforma oferece de modo eficiente e pedagógico.

\section{Descrição da ferramenta: alguns dos principais recursos do Blackboard}

Em junho de 2008 a Universidade de Manchester ofereceu um treinamento para professores interessados em criar cursos virtuais para a complementação das suas aulas presenciais. o principal objetivo do treinamento seria capacitar a comunidade acadêmica no uso dos recursos oferecidos pelo Blackboard e assim expandir o número de cursos online os quais, ao menos no âmbito do SPLAS, ainda estavam aquém do desejável. O treinamento em questão priorizou informações de cunho teórico e genérico tendo o intuito apenas de familiarizar os professores com as principais funcionalidades da plataforma e do ambiente virtual de aprendizagem. Na ocasião sugeriu-se que conhecimentos mais específicos poderiam ser adquiridos posteriormente com a prática.

Os pontos abordados no treinamento consistiram em descrições dos recursos a exemplo da funcionalidade "avisos" (announcements), através da qual os professores podem colocar recados e lembretes para os estudantes de 
duas maneiras: sob a aba (tab) ou o aviso pode emergir como um pop-up no momento em que o aluno abrir a plataforma Blackboard. A função "bate-papo" (chat) permite que alunos que estejam online conversem entre si em tempo real. Essa função provou ser muito popular entre os alunos que, geralmente, já sabem usar programas semelhantes a exemplo do MSN messenger. Já a funcionalidade "debate" (discussion) permite que o professor coloque em pauta um tema sobre o qual os alunos podem desenvolver reflexões e discutir idéias. O recurso e-mail refere-se a um correio eletrônico limitado ao grupo que permite que os alunos troquem mensagens entre si. A função "programa de ensino" (course content) permite que o professor disponibilize os textos e as referências bibliográficas relativas ao curso, inclusive links, artigos em pdf. para baixar ou ler online; também é possível disponibilizar textos audiovisuais como vídeos, podcasts e músicas.

Com a função "calendário" (calendar) os professores podem informar as datas de provas e de entrega de trabalhos. O recurso "módulos de aprendizagem" (learning modes) permite que o professor coloque lições e exercícios adicionais àqueles dados em sala de aula, essa função também pode ser empregada, estritamente, em aulas não-presenciais. A funcionalidade "avaliações" (assessments) permite que o professor disponibilize testes os quais podem ser acessados e realizados através da internet. Com o recurso "atribuições" (assignments) alunos podem ser nomeados pelo professor para apresentar trabalhos e tarefas. O recurso "biblioteca de mídia" (midia library) possibilita a criação de uma coleção de vídeos e outras mídias audiovisuais. A função "outros objetivos" (other goals) permite que o professor estabeleça metas de curto e longo prazo para a classe. Com a funcionalidade "registro" (roster) professor 
e estudantes podem acessar a lista alunos matriculados no curso. Na função "plano de ensino" (syllabus), o programa do semestre para a classe pode ser obtido. Ao utilizar o recurso "quem está online" (who's online) professor e estudantes podem ver quem está conectado naquele momento e estabelecer comunicação.

Além desse treinamento, a Universidade de Manchester oferece em seu website informações sobre a utilização do Blackboard. Entretanto os links e apostilas disponíveis não são um tutorial para professores, apenas informações para os alunos. O uso do Blackboard não chega a ser um problema para os estudantes, pois a plataforma oferece um ambiente virtual relativamente simples de ser usado. Os alunos aprendem rapidamente como acessar o fórum de discussão, usar a função bate-papo e como baixar o material disponibilizado na plataforma. Todavia, para o professor, o uso da plataforma não é tão intuitivo, nem o ato de carregar o material didático escolhido é uma questão direta e reta. Consome-se muito tempo para aprender a usar os recursos e colocar material para os alunos.

Em 2008 e 2009, os treinamentos para a utilização da plataforma Blackboard oferecido pela Universidade de Manchester eram apenas de nível introdutório e priorizavam mais os aspectos teórico-funcionais do Blackboard em detrimento de sessões práticas, explicadas com exemplos de outros cursos já montados. Quando o treinamento é realizado dessa forma, cabe ao professor a responsabilidade de se familiarizar com as numerosas funções da plataforma no seu próprio tempo. Na faculdade de Languages, Linguistics and Cultures (SLLC), o Departamento de Francês é o que se encontra mais adiantado na elaboração de cursos na plataforma Blackboard, graças ao trabalho de um grupo de 
professores que resolveu assumir para si a tarefa de levar parte do curso para o ambiente virtual. Até 2008, no âmbito do SPLAS, não havia nada significativo em termos de cursos oferecidos em ambiente virtual. Os cursos de língua portuguesa elaborados por esse autor e por Ana Sofia Santos, leitora do Instituto Camões, foram os primeiros do departamento a realizar de modo efetivo um programa de ensino virtual complementar às aulas presenciais. Desenvolvido para atender os alunos de graduação em Letras Português, os oito módulos criados abrangeram o maior número possível de funcionalidades do Blackboard buscando oferecer material didático extra, tarefas, aprendizagem enfim, para turmas do primeiro ao quarto ano.

\section{Treinando os professores de maneira eficaz}

Ao contrário do que afirmam as propagandas oficiais sobre a plataforma Blackboard, alguma experiência prévia com esse tipo de tecnologia é necessária. Considera-se esse ponto fundamental para 0 sucesso de experiência de EaD. Familiaridade com a tecnologia é necessária aos alunos, que irão explorar as possibilidades da plataforma. Além disso, - conhecimento tecnológico é ainda mais essencial para professores, pois estes irão elaborar os cursos e gerir o conteúdo programático. Em parte, a subutilização da plataforma Blackboard no âmbito do SPLAS se deve à falta de treinamento direcionado. Sem treinamentos adequados para os professores os numerosos recursos oferecidos na plataforma Blackboard ficam reduzidos à utilização de suas funções mais básicas (e-mail, calendário, plano de ensino, etc.) ; e assim esta ferramenta de ensino se torna apenas um ponto virtual de disponibilização de links e de material didático para download. 
Os treinamentos para utilização do Blackboard poderiam ser aprimorados se fosse ensinado aos professores como abordar de modo prático as funções específicas do programa, ilustrando a parte teórica com exemplos de outros cursos que já foram criados e aplicados de maneira bem-sucedida dentro da instituição. Professores de departamentos que já têm experiência na utilização do Blackboard poderiam ser convidados para os treinamentos a fim de apresentar seus cursos e de compartilhar o conhecimento adquirido. Talvez, um dos motivos para que a experiência bem-sucedida de outros departamentos não seja aberta para a coletividade esteja na questão dos direitos autorais. Não se pretende tratar desse assunto aqui, mas deve-se ressaltar que uma vez na web o material de ensino pode ser baixado e distribuído livremente sem atribuição de crédito/autoria para quem criou o material. Do meu ponto de vista, isso não chegar a ser seja um problema grave, pois, ainda que outro professor utilize um material didático criado por mim, a organização e o resultado da sua aula serão diferentes. Ao deixar o cargo de Leitor na Universidade de Manchester todo - material que criei no Blackboard ficou na instituição à disposição do próximo professor. Desta forma, não creio que a questão de direitos autorais seja um obstáculo para que se compartilhe material didático e experiências de sucesso no uso do Blackboard.

A Universidade de Manchester aposta forte na competência dos seus profissionais para servirem de geradores de conteúdo para a plataforma Blackboard, mas os esforços nesse sentido são incentivados para que se dêem de maneira individual. Não saberia dizer se essa tática tem sido produtiva, pois, no âmbito do SPLAS, os docentes ainda não possuem uma boa atividade na criação de cursos virtuais. E, ao menos em parte, o motivo é a formação necessária para o 
uso desse tipo de ferramenta. Nas últimas décadas as ferramentas de EaD têm se tornado muito relevantes para o processo educacional, a velocidade das mudanças no universo informacional gera a necessidade de atualizações constantes por parte dos professores que almejam acompanhar as transformações tecnológicas. Todavia, se se deseja que os professores assumam a responsabilidade não só de selecionar - material didático e montar o curso, mas também de colocar conteúdo no sistema, então, um treinamento adequado e eficaz se torna condição necessária para uma atuação apropriada nesse domínio.

Não se nega que cabe aos educadores atuais engajarem-se no universo informacional e terem versatilidade suficiente para trabalhar presencialmente e em ambientes virtuais. Entretanto, acredita-se que esse esforço tem de ser coletivo: os professores necessitam do apoio institucional da comunidade acadêmica para encontrarem tempo para atualizarem-se. As mudanças nos paradigmas de ensino geradas pelo desenvolvimento tecnológico são visíveis e aceleradas. Os recursos modernos que estão à disposição atualmente geram novos desafios e o professor necessita incorporar novas práticas a fim de continuar sendo o mediador na construção do conhecimento dos seus educandos. Apenas um treinamento eficaz dos professores irá possibilitar um aproveitamento mais eficaz das ferramentas disponíveis na plataforma e um ensino com propósitos pedagógicos bem definidos.

\section{Considerações finais}

Em conclusão, não basta disponibilizar uma plataforma de ensino, é necessário que se dê treinamento para os professores, até mesmo para aqueles que já conhecem e 
utilizam o Blackboard. A função do professor nessa rede de comunicação não é apenas o domínio tecnológico, mas saber estabelecer um processo de ensino eficiente e produtivo fazendo uso dos diferentes recursos que a plataforma oferece. É necessário produzir a interatividade entre as pessoas cumprindo as funções pedagógicas necessárias para a construção da ambiência de aprendizagem. Os avanços tecnológicos estão tornando a EaD uma modalidade de ensino imprescindível, até mesmo em cursos presenciais enquanto uma complementação e desenvolvimento de questões abordadas em sala de aula. Para que isso aconteça, torna-se necessário preparar o professor para utilizar as tecnologias de ambiente virtual de modo pedagógico almejando formar cidadãos aptos para produzir e interpretar as novas linguagens do mundo atual e futuro.

\section{Referências bibliográficas}

BELLONI, Maria Luiza. Educação a Distância. Campinas: Autores Associados, 2001.

BRASIL. Ministério da Educação. Secretaria de Educação Superior. Educação Superior a Distância. Disponível em: <https://www.planalto.gov.br/ccivil/_Ato20042006/2005/Decreto/D5622.htm>. Acesso em: 08 jun. 2010.

MENDES, Terezinha Marta. EAD: um estudo sobre a ferramenta Blackboard. Monografia UEL. Londrina: 2006.

NISKER, A. Tecnologia educacional: uma visão política. Petrópolis: Vozes, 1993.

SAMPAIO, Mariza Narcio; LEITE, Ligia Silva. Alfabetização tecnológica do professor. Petrópolis: Vozes, 1999.

STANTON, Michael J.; WOLYNEC, Elisa. BLACKBOARD anuncia a liberação do Blackboard learning system mltm em português, para 0 Brasil. Disponível em: <http://www.techne.com.br/imprensa/release22102002.pdf>. Acesso em: 1 nov. 2006. 